\title{
El regreso de la Educación Religiosa a las escuelas públicas: una discusión entre liberales secularizadores y un obispo romanizado $1883-1892^{1}$
}

\author{
The return of Religious Education to the public \\ schools: a discussion between secularized liberals and a \\ Romanized Bishop 1883-1892
}

\author{
José Aurelio Sandí Morales \\ Universidad Nacional de Costa Rica \\ Jeimy Trejos Salazar \\ Universidad de Costa Rica
}

\begin{abstract}
Resumen
El presente artículo pretende explicar el proceso de reincorporación de la Educación Religiosa a la malla curricular de las escuelas públicas en Costa Rica luego de las leyes emitidas entre los años 1884-1886, cuando fue excluida. Antes de esto, se presentará una breve historia de la educación en Costa Rica desde la colonia hasta 1884, para entender el papel jugado por el catolicismo en dicha actividad y uno de los "porqués" del reclamo episcopal por la exclusión en 1884. El intento por reincorporar la educación religiosa fue encabezado por Mons. Thiel, segundo Obispo de la Diócesis de Costa Rica, quien teniendo claro la premisa de evitar la secularización de la sociedad costarricense, luchó para conseguir que la Educación Religiosa volviera a las escuelas estatales.
\end{abstract}

Palabras clave: religión, educación, Iglesia, Estado, romanización

1 Este artículo responde a una iniciativa en conjunto de los autores iniciada desde 2010. El mismo fue creciendo gracias a otras investigaciones realizadas por aparte de cada una de ellos. Por ejemplo, una parte del mismo se elaboró gracias al proyecto 806-B5-228 inscrito en el CIHAC en el año 2015 titulado "La educación en el Ayuntamiento de Cartago antes y después de la independencia (1812-1850)". Por otro lado, fue gracias su tesis doctoral que José Aurelio Sandí Morales tuvo acceso a las fuentes vaticanas y a otra documentación que sirvió para hacer llegar a buen puerto el trabajo que acá se presenta. 


\begin{abstract}
The intend of this article is to provide a more detailed insight during the process of restoring the religious education to public schools in Costa Rica after it was excluded from the educational system because of the laws issued from 1884 to 1886 that were responsible of this exclusion. But before explaining the mentioned topic, it will be given a short overview about the educational system in Costa Rica starting in the colonial period up to 1884 in order to understand not only the Catholicism's role played during this time frame, but also the episcopal claim regarding this arbitrary exclusion in 1884. This endeavor was leaded by Mgr. Thiel, second bishop from the Costa Rican diocese, with the help of the clergy and the Catholic members they had the conviction of avoiding the secularization of the Costa Rican society (this secularization was proposed by the liberal positivists who ruled the country after 1882), Mgr. Thiel made all kind of efforts to restore the religious education to the state schools.
\end{abstract}

Keywords: religion, education, Church, State, romanization

\section{Introducción: La Ilustración, las Reformas Borbónicas y su impacto en la educación}

Durante el período de conquista y colonización en América, la única educación recibida por los indígenas fue la que respondió al proyecto evangelizador. Es así como

... la evangelización de los naturales era tarea primordial, encomendada por la Corona y asumida por la Iglesia como una justificación de la Conquista y como imperativo de aprovechar una coyuntura providencial para salvar millones de almas antes condenadas al infierno. (Gonzalbo 2007, 110)

Para poder asumir semejante tarea, la Iglesia católica contó con el apoyo de numerosas órdenes de regulares (franciscanos, dominicos, jesuitas, entre otros), que se encargaron directamente de la enseñanza de niños y adultos. De hecho, producto de ello, surgieron las primeras universidades y colegios de América Latina; los planes de enseñanza se centraron en la doctrina cristiana, gramática, latín, lógica, teología y filosofía.

La instrucción que brindó la Iglesia católica a los indígenas en países como México, Perú (Lima), Guatemala y Argentina (Buenos Aires), se centró en el aprendizaje del catecismo y oraciones, así como leer, contar y escribir. Estos conocimientos eran básicos ya que "muchos consideraban que permitir el acceso de los naturales a la instrucción superior era tanto como darles armas con las que defenderse contra la imposición de sus conquistadores" (Gonzalbo 2007, 115). Esta conceptualización 
no estaba tan lejana de la que tendrán, durante el siglo XVIII, los impulsores de la Ilustración. Según Buenaventura Delgado, "los ilustrados creyeron en el poder de las luces, pero convenientemente controladas y reservadas a unos pocos. Si las clases más humildes accedían al conocimiento se rebelarían contra la esclavitud y miseria en la que vivían" (Delgado 1998, 138). De esta forma, la Educación Superior se reservó para las clases altas, y mantuvo al pueblo en la ignorancia.

Esta premisa se mantuvo en los países, incluso de América Latina, hasta mediados del siglo XIX cuando las élites se dieron cuenta de que la educación de las clases populares les proporcionaría el ansiado progreso económico. Lo anterior, por medio de la tecnificación de las labores y de la división del trabajo. Antes de este período, la educación se dejó en manos de la iniciativa privada y para quienes tenían los recursos económicos para pagar un maestro particular, es decir, los pobres no tenían acceso a ella. Esto no quiere decir que no se hicieran esfuerzos por crear escuelas públicas a las que pudieran asistir los niños pobres, sino que, en ocasiones la poca asistencia o la imposibilidad de los padres de pagar las sumas solicitadas por los maestros para la instrucción de sus hijos impidió el incremento de la población alfabetizada, y con ello, del número de escuelas.

\subsection{La educación en Costa Rica: sus inicios}

Al igual que en otros países de América Latina, la catequización de los indígenas en Costa Rica inició con las primeras exploraciones al territorio. Según Luis Felipe González Flores, el padre Juan Estrada Rávago y fray Pedro de Betanzos realizaron esfuerzos por catequizar y moralizar la "naciente provincia", además de enseñar a leer, escribir y contar a españoles e indígenas en las iglesias, sacristías y conventos (González 1959, 31). El proceso de catequización durante el período colonial suponía, según lo anterior, que existiera una población indígena dócil, agrupada y obediente, así como iglesias y conventos con espacios para la enseñanza, lo cual es complicado. Algunas hipótesis que se podrían proponer sobre lo difícil que pudo ser el proceso de enseñanza de los indígenas durante los primeros años de la conquista de la provincia son: la falta de infraestructura para realizar dicha labor; lo inestable de las poblaciones agrupadas en los asentamientos creados por los españoles (que impedían que el proceso fuera continuo); las jornadas de trabajo a las que eran sometidas las poblaciones indígenas, que obstaculizaban el proceso de enseñanza y la escasez de maestros doctrineros para que abarcaran toda la población.

La obstaculización del proceso de enseñanza por parte de los 
encomenderos se evidencia en los informes que hacían los obispos y frailes sobre la provincia de Costa Rica. Por ejemplo, en 1610, Fray Agustín de Ceballos escribió una carta al Rey, en la cual informaba lo que acontecía en la provincia. Desde su perspectiva, "los encomenderos estorbaban la doctrina de los indios, no dándoles tiempo para que aprendan" (Quirós 2002, 57). Lo anterior se complementa con los detallados informes hechos por los primeros misioneros sobre la catequización y bautizo de cientos de indios en los pueblos a los que llegaban. El interés por la conversión y catequización fue, conforme avanzaron los siglos, concentrándose en las zonas "no dominadas" o de frontera como Talamanca, aunque a los demás pueblos de indios, como Ujarrás, Quircot, Cot y Tobosi, sí se continuó dándoles "la doctrina y el pasto espiritual y [para que con ello] no se acabasen y desolasen estos pueblos" (Quirós 2002, 324). En este sentido, se veía la enseñanza de la doctrina como una forma de mantener los pueblos agrupados $y$, a la vez, como una forma de salvar las almas de los indígenas. El primer registro que se hace sobre un maestro en la provincia se encuentra en el informe del Obispo Benito de Valtodano de 1623 , en este informe se dejó constancia de que el Presbítero Diego Aguilar fue el primer maestro de escuela en Cartago y Costa Rica por más de cuarenta años (Quirós 2002).
El gobernador de Cartago, Tomás de Acosta (1797-1810), había establecido las escuelas públicas de primeras letras para la instrucción de la juventud, aún en los barrios más distantes de la ciudad, para que los pobres fueran partícipes de ella (Ayuntamiento de Cartago 1950). La primera disposición de Acosta establecía que se daría enseñanza a los hijos varones de cinco años hacia arriba, esto se publicó en 1798, y penaba con ocho días de arresto a los padres que no envíen a sus hijos a la escuela (ANCR, colonial, sign.934 1798). Todo lo anterior demuestra lo siguiente: existía un interés por abarcar todos los barrios de la provincia (incluso la población pobre); que la enseñanza estaba restringida al sexo masculino; lo anticipado en el inicio de la enseñanza de los niños (5 años), y el primer registro existente de que se castigaría a los padres que no cumplieran la disposición. Lo anterior, se mantendrá hasta finalizar el siglo XIX, y se agregaron multas económicas e incluso la eliminación de la patria potestad a los padres que incumpliesen todas las anteriores normas (Código Civil de 1888). Esto indica que, para inicios del siglo XIX, ya existía el deber para los padres, de enviar a sus hijos a instruirse, si esto no era cumplido se verían sometidos a pena de arresto. Esta es una pequeña muestra del control social que recayó sobre los padres.

El 25 de enero de 1800 el Sr. Presbítero José María Esquivel, preceptor 
de gramática, protestó porque querían pagarle -en cacao- el salario que recibía por su trabajo (250 pesos). Ante tal situación, escribió una carta al Ayuntamiento haciendo valer su esfuerzo por enseñar. La valoración de Esquivel sobre la educación y sobre el recinto donde impartía sus lecciones era la de "un establecimiento no solo literario, sino dirigido a la mass fina educación, política cristiana, y civil a unos jobenes de los de mayor lustre de los Patrioticos de esta Ciudad" (Actas del Ayuntamiento de Cartago 1959, 13). El presbítero dejó constancia de su preocupación por el aprendizaje que estaban recibiendo los niños, según él:

(...) añadiendo el que parte de la noche me ocupo en la enseñanza literaria y documentos espirituales como también que en los colegios Reales se observa dar a los niños unas vacaciones mui dilatadas en distintos tiempos del año, qe. con el agregado de los feriados pasquas, y los jueves que son de tabla, se pierden algo mas de seis meses; y atendiendo yo a que la experiencia me ha enseñado qe. de estos asuntos resulta el qe. Los animos de los niños se entibian, olvidan lo qe. han aprendido, muchos se extravían, y los mas aunque vuelvan ya imficionados de perversas costumbres qe. han adquirido me he sugetado llevarme todo el año en peso sin interrumpir la fatiga pa. evitar estos y otros funestos resultos. (Actas del Ayuntamiento de Cartago 1959, 13)
De lo anterior se puede destacar que "la mass fina educación, política cristiana y civil" estaba circunscrita a los "jobenes de mayor lustre de los $\mathrm{Pa}$ trioticos de esta ciudad"; es decir, quienes estaban recibiendo la instrucción, no solo religiosa sino también política y civil, eran los más adinerados de la ciudad de Cartago. Por lo tanto, la anterior disposición de Acosta no se estaba cumpliendo a pesar de que, quien estaba pagando por esa educación, era el Cabildo de Cartago. También queda, en el testimonio de Esquivel, evidencia del tiempo al que asistían a lecciones los niños (alrededor de seis meses), y lo difícil que podía ser para un maestro mantener vigentes los contenidos y el deseo de aprender en sus estudiantes. Es interesante que "muchos se extravían y los mas aunque vuelvan ya imficionados de perversas costumbres". Aquí se demuestra, desde bien temprano en el siglo, la lucha que mantendrán las autoridades, incluso hasta el siglo siguiente, para lograr que los niños aprendieran y permanecieran en la escuela.

Tres años más tarde, el 14 de marzo de 1803, Pablo Alvarado solicitó al Cabildo de Cartago poner una escuela pública de primeras letras en uno de los salones del Hospicio de la Soledad ${ }^{2}$. La respuesta fue la siguiente:

2 Nótese la ausencia de infraestructura escolar para inicios del siglo XIX, esta será también uno de los obstáculos a los que se enfrentó el Ayuntamiento de Cartago durante el período de estudio. 
(...) en atención a la necesidad que hai de dha. escuela y concurriendo en el suplicante las circunstancias qe se requieren se ha acordado qe se le conceda su petición y qe se le considere por estipendio de su trabajo dos rspr cada niño de los qe lean en cartilla, tres pr cada uno de los que lean libro o carta y quatro pr cada uno de los qe escriban y cuenten[...] Que se prohíbe por bando el qe pueda haver otra escuela publica ni secreta de niños a mas de la señalada y qe se compela a los padres de familia a qe pongan sus hijos en dha escuela por ser un asunto tan recomendado por S.M. y tan sutil a la educación de la juventud. Que todo niño de la edad de cinco años a arriba hayan de asistir presisamte. los niños a la escuela indicada; quedando al cuidado del mencionado Dn. Pablo Alvarado [...] (Actas del Ayuntamiento de Cartago 1959, 58)

La cita demuestra que para el Cabildo existía una prioridad por limitar la existencia de otras escuelas, aparte de la señalada (que abriría Pablo Alvarado), probablemente para concentrar la población escolar en una sola institución, esta obligación recaería en los padres de familia. También reconocía la necesidad de crear dicha escuela para el bienestar de la juventud y por ser un "asunto recomendado por $\mathrm{Su}$ Majestad".

De lo anterior se pueden apuntar las siguientes conclusiones sobre la educación en los primeros años del siglo XX en Cartago. Primero, las primeras disposiciones sobre dónde se daría instrucción pública, quiénes asistirían a dichas instituciones y sus edades (cinco años hacia arriba), vinieron del Gobernador Tomás de Acosta, desde 1798. Segundo, se estableció un castigo para los padres de familia (responsables de la educación de sus hijos), que incumplieran los bandos y las disposiciones. Tercero, la creación de escuelas públicas y el nombramiento de los maestros fueron asuntos que correspondieron al Cabildo de Cartago, y tanto la permanencia como la continuidad de estos centros respondieron a la cantidad de niños que asistían. Lo anterior se debió a que

(...) la escasa población asentada en la capital colonial y la dispersión de los vecinos por los campos impidió una matrícula suficiente para financiar un plantel formal. Es por ello que la instrucción se convirtió en un privilegio de las familias más pudientes que podían contratar tutores particulares para sus hijos. (Thiel 2011, 64; González, 40-41, citado por Díaz y Viales 2012, 199 y Fischel 1990, 60)

Además, existió un dominio por parte de la Iglesia católica de los contenidos y la docencia educativa y la doctrina cristiana, como el centro del programa pedagógico (en torno a él giraban las otras materias) (Fischel 1990, 70 y De la Cruz 2009, 1-72). 


\subsection{La educación después de la independencia}

Uno de los primeros proyectos creados por el naciente Estado, en materia educativa, fue la creación de la Casa de Enseñanza de Santo Tomás en 1824. Los estatutos de dicha institución educativa destacaban la importancia de la Ilustración como una forma de brindar el apoyo y la instrucción a los pueblos. También se apelaba a la educación como la forma de riqueza de los pueblos (el progreso y el adelanto eran vistos como riqueza, la educación era el medio para acceder a ellos), y como una forma de cultivar las ciencias. Lo anterior, muestra que para los gobernantes era importante que la población costarricense accediera a la educación. Esta institución, o más bien su mantenimiento, salía de las rentas del tabaco. La disposición de estos dineros a la enseñanza era ya un adelanto.

Este mismo financiamiento provenía del Estado y la enseñanza de la religión ya estaba presente dentro de los programas de estudio. En los estatutos de la Casa de Enseñanza se establecía claramente que se enseñaba Lengua, Filosofía, Derecho y Teología. En la última, se concentraban en la lectura de las Sagradas Escrituras todos los días, abordando el estudio de elementos cristianos y sociales (República de Costa Rica, 6 de abril, 1825).
Como es sabido, la Casa de Enseñanza de Santo Tomás fue cerrada y reorganizada posteriormente, y en 1853 fue declarada Universidad Pontificia. Lo anterior, significaba que:

1. El obispo deberá libremente elegir y destinar el texto para las cátedras teológicas, de Historia Eclesiástica, de Sagrada Escritura y de todas aquellas cátedras que constituyan la facultad teológica.

2. Se instituirá el Colegio Teológico Canónico compuesto de todos los profesores de las indicadas cátedras, del cual será siempre Presidente el obispo temporal.

3. El obispo determinará los ejercicios de piedad que se deban practicar en la Universidad por los jóvenes estudiantes.

4. Vigilará el obispo porque la enseñanza de todas las otras ramas sean conforme a la doctrina de la Fe y de la Moral Cristiana.

5. Queda establecido el cuidado pastoral del obispo sobre la Universidad, el mismo vigilará en un modo especial sobre la conducta religiosa y moral de todos aquellos que compongan la Universidad misma.

6. Los profesores de cualquier ramo de enseñanza harán al obispo las profesiones de fe según la fórmula de S.M. Pío IV y las repetirán en la apertura anual de la Universidad. 
7. El obispo tendrá la misma influencia y atribuciones sobre los colegiandos así como en los 3. 4. 5. y sobre las escuelas de enseñanza de primaria y secundaria.

8. Los seminarios son de total y absoluta dependencia de los respectivos obispos, así como su enseñanza.

9. Será eliminado del estatuto las recomendaciones que se hagan sobre libros prohibidos, ni se recomendarán a los jóvenes otros libros que hayan sido prohibidos. (AHABAT, Fondos Antiguos, caja 48, 1853)

El carácter de Universidad Pontificia le daba una total autoridad al obispo para dirigir la institución, así como la enseñanza que se daba en los ramos de primaria y secundaria. El 17 de diciembre de 1869 se publicaron nuevamente los estatutos de dicha casa de enseñanza, en los que se señalaba claramente el papel de la educación religiosa. En este caso, se estableció la carrera de Ciencias Eclesiásticas, la cual se dividía en 2 ramas: Sagrados Cánones y Teología. Para este momento, la intención no era formar niños sino cumplir con la necesidad de formar profesionales universitarios encargados de enseñar la religión.

También se establecía que mientras se organizaba la enseñanza secundaria en el país, dicha Casa se encargaría de la educación, al impartir las siguientes materias: Humanidades y
Filosofía (Historia Sagrada y Profana, Física, Química y Matemáticas), Artes, Agricultura y Comercio (Agronomía, Economía Política, Geografía, Agrimensura, Derecho Mercantil). Otro de los proyectos de enseñanza para la población fue el de crear, por el término de 5 años, un liceo general para la educación e instrucción de las niñas de todos los departamentos del Estado, en 1847. El objetivo de crear esta institución era destacar:

La importancia de la moral pública, el bienestar social y la educación del bello sexo, de donde sale la hija amorosa que alhaga y dulcifica la ancianidad de sus padres, la fiel esposa que hace la dicha del hogar doméstico, y la tierra madre destinada por la naturaleza, a formar como primera maestra, el corazón de un hombre: persuadido así mismo, de que en el Estado de progreso y de población en que se encuentra Costa Rica, ya es oportuno y preciso erigir casas de enseñanza pública para niñas en todos los departamentos del Estado. (República de Costa Rica, 19 de mayo, 1847)

Lo anterior es importante porque se consideraba a las niñas como las depositarias de la cultura que se debe inculcar a los hijos desde pequeños, cuando se refiere a "primera maestra". También se puede destacar, de la cita anterior, el patriarcalismo imperante donde la mujer era la encargada del hogar y la que velaba por el bienestar de los padres ancianos. En el mismo 
proyecto se menciona el carácter moral y religioso que se debía inculcar en las niñas, tales como principios de lógica de educación cristiana, de moral, de virtud y urbanidad. Esto sin mencionar el bordado, el dibujo, la costura y todo lo que fuere dable y contribuyente a la perfección física y moral de la mujer (República de Costa Rica, 19 de mayo, 1847).

Dentro de estos mismos proyectos de educación que incluían la religión católica costeada por el Estado, se encuentra la creación del Colegio de San Luis Gonzaga en 1842. Esta institución fue regentada por los jesuitas desde 1875 hasta 1884, año de su expulsión del país, ello implicó un fuerte carácter religioso en este centro de educación cartaginés. El objetivo principal de esta institución fue la enseñanza y educación de la juventud de la vieja metrópoli, así como vecinos de otras localidades del país, por ende, desarrollaron, mediante cultura gradual y armónica, sus facultades físicas, intelectuales y morales para formar buenos ciudadanos y hombres útiles para el país. El programa de enseñanza comprendía bachillerato en Artes, estudios superiores de Filosofía y Humanidades, clases extraordinarias de aplicación a la industria y las artes mecánicas, clases de adorno y movimiento y clases de Moral e Higiene. Existía además un reglamento interno compuesto por premios, castigos y normas de comportarse, por parte de los estudiantes.

El reglamento de Instrucción Pública de 1869 establecía que la educación religiosa comprendería el estudio de la Doctrina Cristiana mediante el catecismo que designara el Prelado Diocesano. De esta forma:

La enseñanza de la Doctrina Cristiana deberá verificarse haciendo que los niños la aprendan de memoria, y haciéndoles el maestro sencillas y familiares explicaciones sobre el sentido y origen de las frases y palabras de tal modo que ellos lo comprendan. Para los niños que aún no sepan leer, esta instrucción deberá darse a viva voz. La historia Sagrada se esplicará también por el maestro, con láminas á la vista si fuere posible, y procurando que las esplicaciones estén al alcance de los alumnos. Procurar que aprendan de memoria a la voz viva oraciones y puntos fáciles de la doctrina cristiana, de historia sagrada, de historia de Costa Rica y cuentos y ejemplos morales. (República de Costa Rica, 26 de noviembre, 1869)

Lo anterior evidenció que la religión era parte del programa de enseñanza en las escuelas y que los propósitos de la enseñanza se enfocaban en el aprendizaje, por parte de los alumnos, del contenido de los catecismos. Como parte de los ejercicios de las escuelas (en todas las escuelas era obligatoria la enseñanza de la religión) se les 
pedía a los alumnos que se hiciera un repaso diario de la Doctrina Cristiana. También se establecía que los alumnos asistieran a un repaso de la doctrina los sábados, acompañados del sacerdote de la parroquia. Este explicaría el texto correspondiente a la lección y se encargaría de hablar acerca de las festividades del día siguiente (domingo).

Los domingos y días de fiestas de guardar los niños asistirían a la escuela, donde luego pasarían a la iglesia acompañados por el maestro. Para el caso de los niños que tenían la edad para realizar la primera comunión, eran el maestro y el párroco los que decidían si el niño tenía la instrucción suficiente para recibir dicho sacramento (República de Costa Rica, 26 de noviembre, 1869)3.

3 La primera comunión era fundamental para los niños en edad escolar. Esta solo se podía recibir si el niño tenía los conocimientos que todo cristiano debía tener en el período. Los maestros, los padres y el sacerdote eran los principales encargados de enseñar, desde edades tempranas, al niño las oraciones y la forma de actuar de un buen cristiano. En este punto la educación religiosa impartida en la escuela confirmaba los conocimientos recibidos en el hogar.

\subsection{Los intentos de seculariza-} ción de la educación en Costa Rica ${ }^{4}$

El proceso de secularización se fundamentó en ideas que no se desarrollaron del todo. Según la historiografía costarricense, las leyes de 1884 son el inicio de las tensiones Iglesia-Estado. Tiene relevancia especial el 18 de julio de 1884, cuando se decretó la expulsión del obispo Bernardo Augusto Thiel junto con la Compañía de Jesús ${ }^{5}$, que dirigían el Colegio de San Luis Gonzaga. Además, el 22 de julio de 1884, Bernardo Soto ${ }^{6}$ decretó la prohibición para el establecimiento de órdenes monásticas dentro del territorio costarricense. El principal argumento de dicha orden fue:

4 Para ahondar en el tema puede revisar: Vargas Arias, Claudio. El Liberalismo, La Iglesia y el Estado en Costa Rica. San José, Costa Rica: Ediciones Guayacán. 1991; Solano Muñoz, Edgar. Iglesia, sociedad y relaciones de poder en Costa Rica: 1881 1894. Tesis para optar al grado de Licenciatura en Historia, Universidad Nacional,1993; Blanco Segura, Ricardo. 1884. El Estado, la Iglesia y las Reformas Liberales (San José, Costa Rica: Editorial Costa Rica. 1983); Sanabria Martínez, Víctor. La primera vacante de la Diócesis de San José, 1871-1880. San José, Costa Rica: Imprenta Lehmann, 1935; Sanabria Martínez, Víctor. Mons. Anselmo Llorente y Lafuente. San José, Editorial Costa Rica, 1972; Sandí Morales, José Aurelio. La Diócesis de San José y el Estado costarricense: la creación de parroquias y el control del espacio geográfico nacional, el surgimiento, difusión y consolidación de un ideario de costarricense para arraigar el proyecto Estado-Nación (1850-1920). Tesis para optar por el grado de Magíster Scientiae, Universidad Nacional, 2009.

5 Tenían orden de abandonar el país en las 24 horas posteriores.

6 Impulsor de las leyes anticlericales. 
Art. 2. Que semejantes instituciones se oponen al espíritu liberal de nuestras leyes políticas, así porque viven bajo el imperio de reglas que consideran superiores a las del poder civil, como porque la propaganda que tales órdenes ejercen, introducen la discordia en la sociedad y aún en el hogar doméstico.

Art. 3. Que contraviniendo las leyes del Estado, los individuos de las diversas órdenes religiosas que residen en el país, hacen vida monástica y admiten al noviciado y uso del hábito, hijos del país y extranjeros, con grave mal para la sociedad. (República de Costa Rica, 22 de julio, 1884)

A partir de lo anterior, el Estado costarricense promovió la enseñanza laica. De la misma forma, el artículo le prohibía al clero, en el ejercicio de su ministerio, tener injerencia alguna en la dirección de la enseñanza que se da en los establecimientos costeados con fondos nacionales, o combatir dicha enseñanza por razón de ser exclusivamente laica. El incumplimiento de la disposición anterior tenía como castigo eliminar al clero de la subvención del Estado dedicada al culto católico.

Con el objetivo de restarle poder a la Iglesia católica, el 19 de julio se decretó la secularización de los cementerios y el 18 de agosto se prohibió a los párrocos cobrar por sepultar cadáveres, tema que se abordará más adelante; el 28 de julio se derogó el Concordato (acuerdo entre el Estado y la Iglesia católica suscrito desde 1852); el 30 de julio se prohibió recoger limosna por el culto católico excepto si tenían autorización de los gobernantes; y el 17 de setiembre se prohibieron las procesiones con imágenes fuera del templo (excepto Corpus Cristi, Semana Santa y del santo patrono del lugar). También debe recordarse que el 2 de abril del mismo año, se estableció el matrimonio civil y el 16 de julio el divorcio civil. Si bien es cierto estas normas no se publicaron como parte de las "Leyes anticlericales", sí pretendían minar el campo de acción de la Iglesia (Sandí 2009e, 120; República de Costa Rica 1885, 258-64, 296, 302-3, 314 y 349; y Blanco 1984, 167-8).

\section{Thiel y su búsqueda incesante por reincorporar la Educación Religiosa en las escuelas públicas de Costa Rica (1884-1892)}

Al tener claro el contexto histórico del papel jugado por el catolicismo en la educación en América Latina y en Costa Rica, saltan dos interrogantes que guían el presente trabajo. Estas son: ¿Cómo las estrategias implementadas por Mons. Thiel en el proceso para reincorporar la Educación Religiosa en las escuelas públicas de Costa Rica entre los años 18841892, surtieron el efecto deseado por el catolicismo costarricense, así como por lo propuesto desde la curia romana, según el nuevo modelo de relación 
Estado-Iglesia implementado en el pontificado de León XIII?, y por último, es de intereses conocer ¿cuál fue el comportamiento de los liberales costarricenses en medio de la lucha llevada adelante por Mons. Thiel en su interés por lograr de nueva cuenta la injerencia católica en la educación nacional entre 1884 y 1892 ?

Desde el principio de su exilio Thiel inició el proceso paulatino de cancelar las denominadas leyes "anticlericales" $\mathrm{y}$, de manera consecuente, frenar la secularización que se le proponía a la sociedad costarricense por parte de los denominados liberales. Esto lo hizo mediante dos vías, una fue a través de la información detallada, que enviaba a la Santa Sede, de los hechos acaecidos en el campo político y social del país, esto, para pedir de manera constante apoyo y consejo a Roma sobre cómo debía de actuar ante lo que sucedía ${ }^{8}$. La otra fue una

7 Para leer sobre el tema se recomienda: José Aurelio Sandí, "Las leyes anticlericales de 1884 en Costa Rica; una relectura desde otra perspectiva”. SIWO, № 3 2010, 59-100.

8 Para observar un análisis detallado sobre la información enviada por Thiel a la Santa Sede y dentro de la lógica de la romanización se recomienda leer: Sandí Morales, José Aurelio. La Santa Sede in Costa Rica 1870-1936. Il rapporto politico-religioso e diplomatico tra il governo del Costa Rica, la gerarchia cattolica del Paese e la Santa Sede nel periodo liberale costaricano. Tesi di dottorato. Scuola Normale Superiore di Pisa. 2017; Sandí Morales, José Aurelio. "Costa Rica en la geopolítica de la Santa Sede, La representación papal en Centroamérica entre 1908-1936". Espigas Año XV, № 32 Diciembre 2016, 81-102, 84-5. combinación de acciones, ya que puso en práctica en el territorio nacional las disposiciones generales indicadas desde la colina Vaticana (entiéndase con las encíclicas de León XIII, sobre el liberalismo), pero según la realidad del país que él bien conocía. Esto condujo al obispo a jugar un juego un tanto peligroso, pues debía manejarse, de manera equilibrada, entre las realidades de los hechos y sus actores principales de cada momento.

Como lo han demostrado los trabajos de Solano Muñoz (1993) y Sandí Morales (2012a), las denominadas "leyes anticlericales" fueron más una demostración de poder (entre lo real y lo simbólico) de los liberales que gobernaban, que una verdadera regulación o nuevo orden en la relación entre el Estado costarricense y la totalidad de la Iglesia católica. En Costa Rica nunca hubo una declaratoria de Estado laico y, de la misma manera, tampoco la sociedad transitó totalmente la vía de la secularización, aunque sí hubo un intento. Este último punto lo pretende explicar el actual texto; por ejemplo, para hablar de secularización en una sociedad se debe dar un hecho en particular, las autoridades gobernantes, el pueblo y el clero deben tener claro que lo religioso pasaría del escenario público a lo privado (Mallimaci 2004, 22), y en Costa Rica esto nunca sucedió. Esto a causa de que a los tres actores que jugaban un rol fundamental no les interesó 
realmente lo que podía suceder, ya que tanto el Estado, la cúpula católica y el mismo pueblo sacaban provecho de las uniones entre estas dos instituciones.

Después de su regreso al país en 1886, Thiel le hizo saber a Roma (por una carta escrita desde Guatemala el 18 de agosto de 1886), que ni él, ni nadie del gobierno hablaron sobre su exilio, ni las leyes decretadas entre el periodo 1884-1886 (ASCAES, Costa Rica, 1885-1886, Facs. 1, Pos. 64-6, f. 57). Este accionar de Thiel se explica porque él no quería empeorar las cosas y buscaba, desde ese momento, una solución a los problemas que habían generado las nuevas leyes decretadas en el periodo 1884-1886 para la Iglesia. Thiel, durante el periodo comprendido entre 23 de mayo de 1886 y el 19 de enero de 1888, guardó silencio sobre las leyes antes mencionadas, pero el 20 de enero de 1888 publicó su décima cuarta Carta Pastoral y con ello inició su sistemático proceso en búsqueda de la reincorporación de las materias de Doctrina Cristiana e Historia Sagrada al curriculum de la Educación Pública, por ende, frenar el proceso secularizador de la sociedad costarricense. Acción que realizó de diferentes maneras, por ejemplo, mediante la presión que ejerció a través de sus escritos en diversas cartas pastorales y circulares dirigidas tanto al clero como a los fieles. También tuvo participación en la política y en la clerecía mediante la formación del partido político Unión Católica, que procuraba devolver lo "perdido" por la Iglesia en la década de los '80. Sin olvidar, la publicación de artículos en la revista "El Mensajero del Clero" y el periódico "El Eco Católico" que, de una u otra manera, caldeaban los ánimos de los creyentes. Estos escritos fueron redactados por los propios presbíteros residentes en el país o eran tomados de otros periódicos católicos internacionales. Por último, no se puede obviar los acuerdos a los que llegó Thiel con los nuevos actores de la política costarricense, en especial con José Joaquín Rodríguez y su grupo político, para que la Doctrina Cristiana y la Historia Sagrada regresaran a las escuelas públicas.

Para exponer y analizar lo antes mencionado, se procederá metodológicamente de la siguiente manera: por una cuestión de espacio, así como por una repetición de ideas centrales en los documentos publicados, se utilizarán los textos más característicos de los divulgados por el propio obispo y sus colaboradores. Por ejemplo, entre los años 1888 y 1892, Thiel publicó un total de 8 cartas pastorales que hacían alusión directa o indirecta a la educación religiosa. Del mismo modo, los artículos publicados en "El Eco Católico" sobre la educación en el periodo de 1889 (año de reinicio de las publicaciones de dicho semanario) hasta 1895, año en el cual aún se seguían 
publicando textos sobre el tema, estos suman más de 50. Por ende, se ha tomado la determinación de utilizar solo los documentos más simbólicos de todo este caudal informativo. De igual manera, las quejas o información de sacerdotes que atacaban la educación laica es interminable, no solo la información hallada en el Archivo de la Arquidiócesis de San José es muestra de ello, sino también las investigaciones de Edgar Solano Muñoz y Luis Murillo Guzmán (trabajo inédito 2017). Ahora bien, se expondrán y se analizarán los hechos más simbólicos que produjeron la reaparición de la Educación Religiosa en 1892.

El 20 de enero de 1888, el II Obispo de Costa Rica publicó una carta pastoral directa y clara contra la educación sin doctrina católica y la exclusión de las materias de Doctrina Cristiana e Historia Sagrada. El primer punto que Thiel dejó claro era que hablaría de un tema fundamental para los creyentes en su proceso "de la salvación de nuestra alma inmortal" (Thiel, en Soto 2014, 351), como lo era la Educación Cristiana de los hijos. El prelado indicaba que dicha educación era un hecho imperioso dentro de la responsabilidad de los padres cristianos, ya que era parte de un "deber de la ley natural, sino también un deber de la ley divina, un deber religioso" (Thiel, en Soto 2014, 353); donde cada padre lo debía de realizar de excelente manera, pues de no ser así se garantizaban las penas eternas del infierno. Para dejar esto claro Thiel mencionó que:

Los padres que se descuidan del deber de la educación, se hacen culpables de un crimen gravísimos que les atrae consecuencias fatales para los días de su vida en la tierra y la condenación eterna en la otra vida. Al contrario, los padres que educan bien a sus hijos recibirán la recompensa de su fidelidad no sólo en la otra vida, sino también muy a menudo en esta, como dice la Escritura Sagrada: "Corona de los ancianos son los hijos de los hijos" [Pr 17,6]. (Thiel, en Soto 2014, 354)

Unido a esto, Thiel indicaba que los hijos eran los talentos que Dios había dado a cada padre, por ello, debían hacerlos crecer para el bien del mundo. Además, agregaba que esto se podía realizar mediante el ejemplo, pues, "si las palabras mueven, los ejemplos arrastran" (Thiel, en Soto 2014, 354), y dichos ejemplos se encontraban en la Educación Religiosa, que mostraba cómo debían proceder los cristianos. En esta carta pastoral hay que dejar claro un dato, Thiel en ningún momento hizo alusión a las políticas estatales que iban en detrimento de la Iglesia como él mismo lo indicaba en sus informes a Roma (ASCAES, Costa Rica, 1885-1884, Facs. 4, Pos. 51-6, f. 68) o a los gobernantes que las decretaban, será hasta la décima sétima carta pastoral, del 3 de febrero de 1889 , 
cuando ataque directamente la moral universal propuesta por los liberales.

En el documento de 1889, el Ordinario de San José indicó que solo existía una moral y esa era la moral religiosa católica. Para ello, Thiel exponía que: "para un cristiano no puede haber duda que el único método de educación es la educación "moral religiosa”, por ser el único conforme (con) la verdad" (Thiel, en Soto 2014, 384). Además, agregaba que dicha educación moral religiosa se debía de extender a todas las facultades del hombre, pues sería el carácter religioso el que le permitiría a los niños, que luego serían hombres, saber discernir correctamente y canalizar de manera adecuada todo lo que se podía sentir cuando llegara el momento de vivir sentimientos como: el apetecer, el rechazo, el amor, el odio, la enemistad, la tristeza, la alegría, la esperanza, la cobardía, la audacia, el temor, el gozo, entre otros componentes del diario vivir.

Este conocimiento, que daría la moral religiosa, era para Thiel un punto de quiebre con la moral "laica" o secularizada. Según el obispo, la educación religiosa alimentaba el corazón y la secularizada no lo hacía. La moral "laica" era para el obispo "cuentos morales sin sal ni vigor" (Thiel, en Soto 2014, 400), que solo se querían incorporar a las nuevas pedagogías que no daban mayor aporte a la sociedad.
Con este documento Thiel abría fuego directo contra el Estado y su proceso de secularizar a la sociedad, al sacar de ella la Educación Religiosa de las escuelas públicas. Después de este texto, fuese en "El Eco Católico" o en el "Mensajero del Clero", o en las homilías del prelado y de la clerecía, que los ataques al gobierno fueron directos y no solapados. Con estos dos escritos publicados por el propio obispo, se dejaba en claro que quien no educaba a sus hijos bajo la doctrina cristiana podía ir al infierno y que la moral "universal" no era la indicada para educar a un niño católico. Con este arsenal de información y condenas, el clero se dedicó a predicar estos hechos y técnicamente el pueblo a obedecerlo, no en su totalidad, pero sí en una gran mayoría. No se puede olvidar que unido a prédicas y a la publicación de artículos apareció un partido político católico, entre cuyas funciones estaba el recuperar la Educación Religiosa en las escuelas, pero de esto se hablará más adelante.

En "El Eco Católico", como se ha dicho, se publicó un gran número de artículos sobre los peligros de la secularización del sistema educativo. Por ejemplo, estos artículos empezaron a publicarse desde 1883, pues el mismo Thiel, previendo el actuar de los liberales, sabía que más temprano que tarde la reforma en la educación vendría. Tanto es así, que como lo cita Esteban Sánchez en la homilía de la misa de 
Pascua de 1883, el prelado indicó que "Vigilemos sobre la educación religiosa de nuestros hijos, y no permitamos bajo ningún punto de vista que frecuenten escuelas o colegios de segunda enseñanza [de] las cuales se excluye la enseñanza religiosa" (Sánchez 2013, 97). Luego de este mensaje se publicó, en "El Eco Católico", un artículo titulado "La enseñanza monacal", en el cual se expuso que:

Y he allí a nuestros liberales entonando himnos báquicos a la Libertad, en el momento mismo en que ejercen el más odioso despotismo sobre las conciencias y quitan a los padres de familia el más santo e inenajenable de sus derechos, el de alimentar el alma de sus hijos con las enseñanzas que ellos creen hará su felicidad, y obligándoles a aceptar maestros y doctrinas que repugnan a su inteligencia y corazón... (Sánchez 2013, 66)

La cuestión con los artículos publicados en "El Eco Católico" tanto en 1883,1884 y todo el periodo entre 1889-1895 fue que se centraron dos argumentos específicos. El primero de ellos era que la idea de secularizar la educación era un plan fraguado por los liberales y los masones ${ }^{9}$ en conjunto, los cuales, unidos a las nuevas ideas

9 Para observa un excelente análisis de los discursos católicos anti-masones se recomienda leer: Ricardo Martínez, "Documentos y discursos antimasónicos católicos en Costa Rica (18651899)" REHMLAC Vol. 1, № 1 (mayo-noviembre 2009): 135-54. del racionalismo y el indiferentismo, pretendían sacar la religión de todo campo $^{10}$. El segundo punto era que la denominada educación "laica" no era neutra, pues era estrictamente anticatólica, esto la convertía automáticamente en una educación parcializada.

Si bien es cierto, muchos de los ideales perseguidos por los masones costarricenses de la segunda mitad del siglo XIX concordaban con las propuestas de los liberales del mismo periodo, no se puede argumentar que la reforma educativa llevada adelante en Costa Rica, desde 1868, respondía solo a ideales liberales-masónicos. Los mismos Jesús Jiménez y Mauro Fernández no fueron masones, por ejemplo, Jiménez Zamora era un fervoroso católico y declarado anti-masón. Por su parte, como bien lo demuestran el trabajo de Ricardo Martínez sobre la masonería en Costa Rica en el periodo 1865-1899, el principal guía y líder de reforma educativa en tiempos de los liberales: Mauro Fernández Acuña, no era masón (Martínez 2017b). Sin embargo, la jerarquía católica costarricense, como muchas en el mundo occidental, no veía tal diferencia entre liberales y masones (Conti 2003), muestra de ello fue el artículo publicado el 31 de marzo de

10 Pedro Arnáez y Rubio, "La escuela sin enseñanza religiosa o la ciencia sin Religión,” Eco Católico, 17 de febrero de 1883, 58. Este artículo se presentó en el semanario en tres entregas, siendo la primera el 17 de febrero y la última 10 de marzo de 1883 . 
1883 titulado "Los Principios Masónicos aplicados en Costa-Rica", en donde se indicaba que:

La sociedad entera en todas sus instituciones no debe reconocer más que al dios: Estado.

Por esto abajo la enseñanza religiosa. En la escuela no se hablará más de Dios. Los niños deben aprender que el Gobierno es dios. Pues la enseñanza irreligiosa ya tenemos ${ }^{11}$.

Sin duda, esta idea muestra el análisis que realizaba la cúpula católica, donde presentaba la idea de una educación "laica" como un postulado liberal-masónico. Esto generó, entre la población, la idea de que tanto liberales como masones eran uno mismo en esta propuesta de secularizar la educación costarricense. Se debe aclarar que, en ningún artículo, homilía o carta pastoral de Thiel o del clero a su cargo, se hizo una diferenciación entre masones y liberales, por ende, unido a todo lo que condenaba el Syllabus ${ }^{12}$ de 1864 , se estableció que liberalismo, masonería, racionalismo, indiferentismo y

11 "Los Principios Masónicos aplicados en Costa-Rica," El Eco Católico, 31 de marzo de 1883.

12 En este documento publicado en 1864 junto a la Encíclica papal "Quanta Cura", Pio IX condenaba lo que él consideraba los errores de la modernidad. El panteísmo, el naturalismo, el racionalismo absoluto y el indiferentismo fueron condenado entre los puntos I al XV. Las sociedades secretas y los errores que eliminaban derechos a la Iglesia fueron condenados entre los puntos XIX al XXXVIII. E. ROSSI, (a cura di). Il Sillabos, Parenti, Firenze 1957. demás errores de la modernidad eran hijos de lo que había sucedido en la Revolución Francesa. Todo esto era presentado como parte de un solo cuerpo maligno que combatía la verdadera religión, que era la católica ${ }^{13}$.

Thiel, durante todo su episcopado, combatió todos estos males, por ende, permitió la publicación de artículos en el mismo semanario donde se avalaba el papel del catolicismo en el progreso educacional y científico de los pueblos. Como se muestra en el artículo publicado el 17 de febrero de 1883, se indicó que no había error más grande que asegurar que la Iglesia o el catolicismo conducían con sus doctrinas al oscurantismo y que más bien

13 Para dejar este argumento claro, a los feligreses del país, la jerarquía católica publicó de manera constante en "El Eco Católico" una seria de artículos entre el 31 de marzo y 5 de julio de 1884, que hacían referencias a los problemas que enfrentaba la Iglesia y la educación religiosa en países como México, Alemania, España, Italia, Nicaragua, Bélgica, Colombia, entre otros, a causa de la masonería, el liberalismo y el indiferentismo. Estos artículos publicados en el periodo indicado llevan títulos como los siguientes: “¡Siempre lo mismo y los mismos!, Educación en Colombia, La Frac-masonería, Circular masónica, La Franc-masonería y las enseñanzas perniciosas en Nicaragua, Desesperación del Racionalismo, El Monstruo político, El Indiferentismo, Imposturas del monstruo político, Los católicos liberales no son católicos" entre muchos más. Esto deja claro cuál era la visión y ataque del clero costarricense, hacía un frente común contra todos estos males que consideraba parte de un uno más grande, que era la idea de sacar a Dios de la sociedad, para llegar a un fin máximo que era la separación entre el Estado y la Iglesia y obviamente eliminado la educación religiosa de las escuelas públicas. 
era gracias la revelación divina que la razón podía "llegar á conocer aquel orden de verdades con más facilidad, seguridad y sin mezcla de errores" (obviamente se hace alusión directa a la "Summa Teologica" de Santo Tomás de Aquino). Para ello daban ejemplos de cómo figuras del catolicismo rescataron instituciones de enseñanza que estaban destinadas a la desaparición, como cuando "la Universidad de Oxford estaba á punto de ser arruinada, cuando el Canciller de Eugenio III, Roberto Pullus, Cardenal la restauró sosteniéndola en parte á expensas suyas"; o que fue gracias Gregorio IX que la Universidad de París, en 1229, cobró de nuevo vida gracias al papel desempeñado por este pontífice; o por el Papa Urbano V que instituyó la Universidad de Cracovia, por solicitud del rey Casimiro; o la fundación que hizo de un colegio de médicos en Montpellier o los 1000 estudiantes que sostuvo con sus rentas en diversos colegios ${ }^{14}$.

Para 1889, aunque el discurso del liberalismo-masónico como responsable de la laicización del sistema educativo costarricense no desapareció, la jerarquía católica costarricense dio fuerza a otro argumento; este era que la educación neutra ("laica") no era neutra. Para 1889, cuando volvieron las publicaciones del semanario católico,

14 "El verdadero Progreso es debido en su mayor parte al Catolicismo," El Eco Católico, 17 de febrero de 1883 . hasta 1892, los principales argumentos fueron dos: 1) la educación "neutra" no es "neutra" y 2) publicar los planes que tenía la clerecía del país para recuperar injerencia para regir toda la educación del país. En primer lugar, se indicaba que la educación no era "neutra" porque no se hablaba de Dios, por ende, era anti-católica e inmoral ${ }^{15}$.

Para la cúpula católica "el silencio del maestro sobre religión lejos de ser un acto de neutralidad es una enseñanza de ateísmo práctico ${ }^{16 "}$. Por ello se estaba en contra de la religión de la mayoría de los costarricenses, la cual debía prevalecer como bien público, sobre el particular y "deseos y comodidades de unos pocos... que no llegan siquiera á una mínima cantidad ${ }^{17}$ ". Para terminar de darle fuerza a este argumento, el 1으 de febrero de 1890 se publicó un texto cuyo inicio indicaba que: "El que no está conmigo está contra mî", y que la educación "neutra" era parte de la estrategia de los que estaban en contra de la Iglesia y Jesucristo, el Hijo de Dios, ya que la neutralidad para Cristo era igual "a la indiferencia, al desprecio, al desacato, al sacrilegio, siendo nada menos que un crimen de lesa divinidad ${ }^{18 "}$.

15 "Breves disertaciones sobre la enseñanza laica," El Eco Católico, 18 de enero de 1890.

16 "Breves disertaciones sobre la enseñanza laica," El Eco Católico, 11 de enero de 1890, 17.

17 "El catolicismo y la Enseñanza," El Eco Católico, 25 de enero de 1890 .

18 "La enseñanza neutra no es neutra," El Eco Católico, 1 de febrero de 1890 . 
Este tipo de mensaje fue el que se le presentó a la feligresía costarricense. Si bien es cierto no se puede argumentar que todos los católicos estaban alfabetizados, el impacto del semanario era importante dentro del grupo de católicos del país. El semanario era texto "base" en las diferentes reuniones de los católicos costarricenses; además, era un documento que Thiel y el clero pedían que fuese comprado, así como leído por los letrados a los analfabetos. Como se verá más adelante, estas condenas a la masonería y al liberalismo, publicadas en cartas pastorales y en "El Eco Católico", calaron sobre el pensar del costarricense-católico promedio para enviar a sus hijos a las escuelas públicas.

Por su parte, en la revista "El Mensajero del Clero", entre los años de 1891 y 1892 , se publicaron varios textos sobre la Educación Religiosa con el objetivo de que fueran leídos por la clerecía del país. Lo anterior fue para dejarles claro a los sacerdotes cuál era el modo de pensar de la cúpula católica costarricense, así como cuál era el actuar y proceder del Partido Unión Católica, -agrupación que se asignó el deber de defender los derechos perdidos por parte del catolicismo costarricense en la década de 1880- (Sánchez 2013, 269-81). El 31 de enero de 1891, se publicó un artículo donde se exponían las determinaciones que había tomado el episcopado de los Estados Unidos sobre la Educación Religiosa.
De manera sistemática el artículo presenta cómo los obispos de Cleveland, Nueva Orleans, Nesqually, la isla de Vancouver, Buffalo, Trenton Cincinnati, Louisville, les plantearon a sus feligreses no enviar a sus hijos a escuelas públicas ("laicas"), a no ser en caso extremo, ya que según palabras de Mons. Farrel, Obispo de Trenton, estas escuelas no católicas:

$1^{\circ}$ No educan, pues no perfeccionan el corazón..., (este argumento es muy similar al expuesto por Thiel en la décima sétima carta pastoral), 2을 No instruyen bien..., $3^{\text {o }}$ no son verdaderamente americanas..., $4^{\mathrm{o}}$ son anticristianas y adaptadas á destruir los principios de la religión de Jesucristo en las generaciones venideras, $5^{\circ}$ tiene á debilitar las leyes de la moralidad y á quitar todo freno á las pasiones ${ }^{19}$.

Además, se exponía que ese tipo de escuelas propiciaban la lectura de libros "malos y perniciosos", y que si un padre, teniendo una escuela católica cerca, los enviaba a las escuelas públicas incurría en pecado. Este comportamiento, para el episcopado norteamericano, era tan grave que los niños-católicos enviados a escuelas públicas no podían "ser admitido á la primera Comunión ó á la Confirmación”, pues al no estar al menos un año en una escuela católica no tenían la

19 "Actitud de la jerarquía católica en Estado Unidos con las escuelas públicas," El Mensajero del Clero, 31 de enero de 1891. 
formación mínima para acceder a dichos sacramentos ${ }^{20}$.

Este argumento, expuesto en revista mensual, es de suma importancia, ya que se enmarca en la lucha que un año antes tuvo el obispo Thiel con Ricardo Jiménez, Secretario de Culto. En diciembre de 1889, Thiel indicó a los padres de familia no enviar a sus hijos a "escuelas dirigidas por maestros o maestras protestantes o libres-pensadores, menos aún á escuelas cuyo personal docente está constituido en su mayor parte de protestantes ó libre-pensadores $^{21}$ ". A dicha propuesta episcopal, Jiménez Oreamuno, indicó que el obispo incumplió la orden establecida donde se prohibía atacar la educación laica decretada por el Estado.

Ante esta acusación, Thiel mencionó que no había atacado a toda la educación estatal, solo a las que eran dirigidas por protestantes y libres-pensadores, que no eran la mayoría, ya que, de las 400 escuelas estatales, los protestantes y libres-pensadores solo administraban un bajo número. Sin embargo, aun así, él como pastor de su pueblo, no quería ni debía permitir que los hijos de los católicos las frecuentasen, ya que supo que

20 "Actitud de la jerarquía católica en Estado Unidos con las escuelas públicas," El Mensajero del Clero, 31 de enero de 1891.

21 "Señor Secretario de Culto Lic. Don Ricardo Jiménez, San José. Sipurio de la Talamanca á 9 de Enero de 1890," El Eco Católico, 8 de febrero de 1890 .
(...) una directora protestante le dijo á sus discípulas que la religión protestante es mejor que la católica; 2 ㅇ. que la misma directora en días de fiesta pretendía ocupar á sus alumnas en trabajos de mano, no permitidos á los católicos en los días de guarda ${ }^{22}$.

Con esto, Thiel dejaba claro tanto al gobierno, al clero como a la feligresía, su proceder; él, como pastor a cargo de las "ovejas" costarricenses, no permitiría que la educación "laica" atacara al catolicismo. Por esto, si era del caso recomendar el no envío de los niños a este tipo de escuelas lo haría, como lo hizo, por medio de amenazas con las penas eternas a los padres y tutores que descuidaran la educación de sus hijos al dejarla en manos de protestantes o libres-pensadores.

Las estrategias de Thiel para que los hijos de los católicos se educaran bajo su fe no se quedaron en publicar cartas pastorales o hacer que los encargados del semanario y la revista diocesana publicaran artículos sobre el mismo tema, utilizó otros métodos. Por ejemplo, se puede citar la creación de juntas de educación religiosa en cada parroquia, así como la aparición de un partido político que lucharía de manera directa con los liberales para recuperar lo perdido por los católicos. Las juntas de la Sociedad de la Doctrina

22 "Señor Secretario de Culto Lic. Don Ricardo Jiménez, San José. Sipurio de la Talamanca á 9 de Enero de 1890,” El Eco Católico, 8 de febrero de 1890. 
Cristiana eran las "encargadas de organizar la educación religiosa en las parroquias" durante el periodo cuando la Educación Religiosa no estaba dentro del curriculum escolar. Su impacto fue fuerte en el país, ya que en 52 parroquias existió dicha sociedad, llegó a tener un total de 500 maestros en todo el país (Sánchez 2013). Esto muestra, sin duda alguna, que Thiel utilizaba todo lo que tenía a su disposición para recuperar lo que consideraba perdido. Aún más, este comportamiento se dio con el claro fin de frenar el proceso de secularización de la sociedad costarricense que los liberales proponían. Proposición presentada para Thiel de la siguiente manera: sacar la Educación Religiosa de las escuelas pública era una muestra inobjetable del tránsito secularizador, pues lo religioso pasaría solo al ámbito privado, y abandonaría el público. Ante esto, apareció una nueva estrategia, ahora llamada partido político "Unión Católica".

El partido "Unión Católica” fue una agrupación de carácter político, que en sus principios estaba defender a la Iglesia y, por ende, atacar a sus enemigos. Muestra de ello fue lo acordado en la reunión llevada a cabo el 25 de febrero de 1892, por parte de la Unión del Clero (Sánchez 2013), grupo que era parte de la agrupación política. Lo acordado se centraba en atacar sistemáticamente al liberalismo, por ser este condenado por la Santa Sede, a causa de sus propuestas de libertad que iban contra el plan de Dios, porque dentro de sus ideas estaba la defensa y consolidación de "la enseñanza sin Dios ${ }^{23}$ ". Con este panorama claro sobre las intenciones de Thiel y de su proceder, fuesen quienes fuesen los gobernantes del país, sabían a qué se enfrentarían: al obispo, a la mayoría de clero y a la mayoría de sus feligreses que estaban decididos a conseguir el regreso de la Educación Religiosa al curriculum de las escuelas públicas costarricenses. Luego de esto, lo sucedido dentro de esta historia fueron las negociaciones y el consenso al que llegaron los hombres con poder, entiéndase José Joaquín Rodríguez Zeledón, presidente del país entre 1890-1894 y Mons. Thiel para que regresara la Educación Religiosa.

\section{La estrategia política de Mons. Thiel para que la Educación Religiosa volviera a las Escuelas Públicas 1889-1892}

Durante las elecciones de 1889 , Mons. Thiel jugó un doble juego, esto en búsqueda de asegurarse que quien fuese el vencedor de dichas contiendas le garantizase libertad a la Iglesia católica. Como lo demuestran los trabajos ya citados de Solano Muñoz (1993), Sandí Morales (2012), Sánchez Solano (2013) y Murillo Guzmán (2017), Thiel, en un inicio, se declaró neutral, pero al poco tiempo dio su adhesión

23 "La Unión del Clero," El Mensajero del Clero, 31 de mayo de 1891. 
a Ascensión Esquivel Ibarra. Sobre el candidato liberal el prelado argumentó que según "Mi opinión personal está en favor del señor Esquivel: 1) Por cuanto el Señor Esquivel me ha dado garantías para la Iglesia, en cuyo cumplimiento creo; 2) Porque mis circunstancias personales me llevan a pensar asî" (Sanabria 1982, 348). A los pocos días de declarar esto comenzaron a llegar un sinfín de cartas a la curia josefina en las que se preguntaba si lo dicho por el obispo era cierto. Tanto fue el caso, que el propio Thiel mandó a publicar, el 12 de octubre, un documento en el cual se indicaba que "ningún partido haga en adelante uso del nombre del Señor Obispo en sus publicaciones ${ }^{24 "}$. Esta publicación respondió al hecho de que también los "rodriguistas" presentaban a su candidato como el candidato católico y defensor de la Iglesia por excelencia. El 15 de octubre de 1889 José María Jiménez, le preguntó a Thiel cómo podía apoyar a Esquivel, si él era conocido por su masonería y su deseo de atacar a la Iglesia y al propio obispo $^{25}$. Thiel, ante tal interrogante, respondió lo siguiente:

1ำ examinando á noche de nuevo con el Lic. José Rodríguez las listas de Masones que tengo en mi archivo no hemos encontrado en ninguna el nombre de Lic. Asc. Esquivel,

24 AHABAT. Fondos Antiguos, Caja 389. San José, 12 de octubre de 1889, f. 350.

25 AHABAT. Fondos Antiguos, Caja 389. San José, 15 de octubre de 1889 . Folio 362-365v. $2^{\circ}$ que no tengo otro anhelo, sino que lleguemos á una elección pacífica y ordenada; $3^{\circ}$ deseo que quien fuera electo, la Iglesia obtenga el rompimiento de una ú otra de las muchas cadenas que la tiene esclavizadas en Costa Rica ${ }^{26}$.

Con esta respuesta Thiel contradecía las mismas palabras que había enviado a Roma en los años de su exilio sobre Esquivel Ibarra en uno de sus informes. El obispo le indicó a la Santa Sede que

Ascensión Esquivel, [era] masón: si bien expresó su oposición contra mi regresó ciertamente contra mi persona no tenía nada, pero él y sus amigos todos masones de América Central de ninguna manera quería que los Obispos en América Central regresaran hasta que el fanatismo religioso fuera erradicado ${ }^{27}$.

¿Cómo se puede entender este comportamiento de Thiel, si sabía que Esquivel era masón y que estaba en contra no propiamente de él, pero sí de la Iglesia? En este momento Thiel jugó su doble juego, ya que, si por un lado dio la adhesión a Esquivel, al punto que el cura de Aserrí, José Badilla lo secundaba ${ }^{28}$, permitió libremente que el resto de los presbíteros del país hicieran propaganda contra Esquivel y a favor de Rodríguez, sin que el prelado to-

26 AHABAT. Fondos Antiguos, Caja 389. San José, 18 de octubre de 1889 . Folio 371.

27 ASCAES, Costa Rica, 1884-1885, Pos. 64-66, fasc. 11. F. 4.

28 AHABAT. Fondos Antiguos, Caja 389. San José, 5 de octubre de 1889 . Folio 340. 
mara determinación alguna. Ejemplos de esto sobran, como el caso del cura de la parroquia de Heredia, Ezequiel Martínez, a quien los "esquivelistas" los acusaron de "trabajar descubierta y directamente en favor de la candidatura de "Rodríguez", con predicaciones en el mercado, en las entradas y salidas de la Iglesia y en el Cantón de San Rafael" (Solano 1993, 160-1).

Ante esta y otras acusaciones, la respuesta de Thiel fue el silencio. Esto debe ser entendido desde la siguiente perspectiva, si ganaba Esquivel (fuese democrática o fraudulentamente, como Bernardo Soto lo quiso hacer), Thiel podía argumentarle a este liberal su declaración abierta de apoyarlo, pero si vencía Rodríguez, como pasó, Thiel le recordaría que el clero trabajó para él, no solo en la campaña, sino en la defensa de su victoria en la noche de los machetes del 7 de noviembre de 1889 (Molina, 1989a, 185 y Solano, 2010, 5-21). Además, hay fuertes indicios que hacen sospechar que Thiel comunicó esta estrategia a Rodríguez Zeledón, ya que, si en verdad Esquivel Ibarra le aseguraba garantías a la Iglesia, ¿qué hace una carta enviada a Rodríguez por Thiel en la cual le solicitaba cumplir su acuerdo de regresar la Educación Religiosa a las escuelas públicas luego de su victoria electoral? (Solano 1993).

Con José Joaquín Rodríguez Zeledón, en la silla presidencial, cualquiera podía pensar que el regreso de la Educación Religiosa a las escuelas costeadas por el Estado sería solo cuestión de tiempo, pero no había nada más alejado de la realidad que esto. José Joaquín Rodríguez no gobernaba solo, dentro de su mismo grupo existían liberales en contra de la jerarquía de la Iglesia católica (él mismo era liberal, pero católico, por más contradictorio que suene, en Costa Rica y en América Latina esto fue una constante), sin olvidar que los liberales que apoyaron a Esquivel lograron ganar escaños en el Congreso Nacional. El alto clero costarricense era consciente de esto, por ende, apenas llegó Rodríguez al poder le hicieron saber qué esperaban de él. En medio del Te Deum del 8 de mayo de 1890, llevado a cabo en la Catedral Metropolitana en acción de gracias por el nuevo presidente, el sacerdote Domingo Rivas Salvatierra le recordó que todos los males que la Iglesia sufría desde 1884 eran a causa de que "Dios ha sido relegado al interior de los templos y al santuario de la vida doméstica, al desterrarse de la enseñanza oficial la doctrina de Cristo" (Sanabria 1982, 343). De este modo, tanto Rodríguez como el resto de liberales, conocían lo que la clerecía esperaba que se corrigiese en este nuevo periodo constitucional.

Con fin de tratar de concluir con las pugnas entre católicos y liberales por la cuestión de la Educación Religiosa, el presidente Rodríguez estableció un acuerdo que permitía este tipo 
de educación a los niños del país. En su intento de dejar contento a católicos y a liberales, Rodríguez decretó el 13 de junio de 1890 mediante el Acuerdo Ejecutivo no 81, lo siguiente: art. 1o que se eximía a los estudiantes de escuelas y colegios de asistir a lecciones los sábados de 11 de la mañana a 2 de la tarde, para que, si sus padres y tutores lo tenía a bien, fuesen a recibir educación religiosa en los cursos de Historia Sagrada y Doctrina Cristiana. Por último, ese mismo acuerdo establecía que era responsabilidad del Ordinario de San José reglamentar esa educación y estableciera quienes serían los maestros, así como que de la Cartera de Culto saldrían los eventuales para pagar a los maestros hasta un máximo de mil pesos al mes (República de Costa Rica 1890, y Arce 1997).

Si bien esto no era lo que deseaba la jerarquía católica Thiel no desaprovechó el tiempo y mandó una circular para el clero y los fieles, donde argumentaba la importancia de la educación religiosa. El 15 julio de 1890 se publicó dicha circular, en la cual el prelado indicó al clero que era importante informar a las parroquias donde existía la fundación de la "Sociedad de la Doctrina Cristiana" lo dispuesto por el Ejecutivo, para que llevaran adelante la educación de Doctrina Cristiana e Historia Sagrada. Esta sociedad fue importante para Thiel y el credo católico, durante los años en que la Educación Religiosa no estaba en las escuelas públicas (1886-1890), pues como lo indicó el sacerdote de Alajuela Gregorio José Benavides “... las clases de catecismo en esta ciudad y sus barrios están bien organizadas, a las clases de catecismo concurren los sábados a la de varones 115 alumnos y a la de niñas 120" (Solano 1993, 177). Thiel sabía esto, por ende, en la misma circular señaló que a la mayor brevedad se le comunicará la posible lista, tanto de hombres como mujeres, y sacerdotes propuestos como un "maestro o maestra de enseñanza religiosa tanto en el centro como en los barrios de las parroquias $^{29 "}$ ". El obispo hizo hincapié en la prisa por obtener la información, pues debía enviarla pronto a la Secretaría de Hacienda y de Instrucción Pública para solicitar la concesión de $\$ 1000$, que el Gobierno Nacional daría "a favor de la enseñanza religiosa".

En este mismo documento Thiel recordó de nueva cuenta lo importante que era la Educación Religiosa. El Ordinario pidió a todos los sacerdotes "transferir para otras horas las demás ocupaciones que podrían presentarse, como son, informaciones matrimoniales, administraciones del Sacramento del Bautismo, etc: siendo solamente eximido según el artículo 3o el caso de una administración URGENTE ${ }^{30 ",}$

29 AHABAT, Fondos Antiguos, sin Indizar. Caja 19. San José 15 de julio de 1890. Folio 159.

30 AHABAT, Fondos Antiguos, sin Indizar. Caja 19. San José 15 de julio de 1890 . Folio 159. 
para otras horas que no fueran de las 11 de la mañana hasta las 2 de la tarde de cada sábado. Thiel era un hombre de fe, pero a la vez consciente de que los niños no llegarían a las lecciones por acción de la Divina Providencia o solos, por ello instó “...á los padres de familia á que no se descuiden de enviar sus hijos á las clases de religión, que deben darse todos los sábados de las once de la mañana á las dos de la $\operatorname{tarde}^{31}$ ". El obispo terminó su circular no sin antes agradecer al

Gobierno Nacional por el importante paso que ha dado dando una prueba clara de los sentimientos de equidad que le animan, probando así que nuestra Patria puede esperar toda clase de bienes de un gobierno que se propone hacer justicia a todos ${ }^{32}$. (la negrita es propia del texto original)

Para remachar todo lo dicho, Thiel publicó, el 6 de enero de 1891, su vigésima primera Carta Pastoral, en la cual expresó como la moral "laica" vino a cambiar todo lo existente antes de 1885. En sí, el texto era una nueva crítica a la educación secularizada, la cual, era presentada como insuficiente para la sociedad, si se comparaba con la propuesta por parte del catolicismo, pues además de ser mejor, formaba buenos y mejores ciudadanos (Thiel, citado por Soto 2014).

31 AHABAT, Fondos Antiguos, sin indizar. Caja 19. San José 15 de julio de 1890. Folio 157.

32 AHABAT, Fondos Antiguos, sin Indizar. Caja 19. San José 15 de julio de 1890. Folio 159.
A pesar de que el acuerdo daba cierta libertad a la Iglesia para educar, los liberales quedaron relativamente satisfechos, pues no era lo que el clero quería. El presidente Rodríguez fue claro e indicó que en dicho acuerdo "no se da injerencia alguna a la Iglesia en la dirección de la enseñanza del Estado", solo un permiso para los niños que sus padres los quisieran enviar a las clases de Educación Religiosa. Poco tiempo después, el partido católico presentó su disconformidad con el Acuerdo, ya que lo veía débil, pues para ellos podía ser eliminado por nuevo mandatario sin mayor discusión. Como el tema se volvía ya en algo inmanejable para Rodríguez por la presión del clero y los argumentos de los liberales, tomó la determinación de presentar el 3 de mayo de 1892 un proyecto de ley sobre la Educación Religiosa que establecía en tres artículos lo siguiente:

Art. 1 Establécese en las escuelas primarias del Estado la enseñanza oficial de la Doctrina Cristiana e Historia Sagrada, impartida por los respectivos maestros con la extensión que el reglamento y programa les den. Art. $2^{\circ}$ Esta enseñanza se dará en todos los grados de la escuela primaria a todos los alumnos cuyos padres, tutores o encargados no manifiesten por escrito y en la forma reglamentaria, decisión en contrario. (Sanabria 1982,379 ) 
Por último, el tercer artículo derogaba el acuerdo 81 del 13 de junio de 1890 (Sanabria 1982).

La discusión sobre el proyecto fue enérgica y hubo opiniones encontradas sobre el tema. Los liberales se oponían de manera rotunda, porque era entregarle a la jerarquía católica la mitad de lo que se le había "quitado" entre los años 1884-1886. Por su parte, dentro de los católicos las opiniones eran divididas, Nicolás Oreamuno y el sacerdote Juan de Dios Trejos apoyaron el proyecto. Por su parte la "Unión de Clero de Costa Rica” refutó el proyecto, y argumentó que no llenaba "las aspiraciones del pueblo, y vulnera y usurpa los fueros de la Iglesia...y porque la nueva ley reduciría enseñanza religiosa a peor condición de aquella en que hasta ahora estaba ${ }^{33}$ ". Como es obvio, los liberales representados por José Astúa Aguilar, también expresaron su oposición al proyecto. Frente a estos hechos, todo aparentaba que los católicos no sabían ni que querían, pues, mostraban un desconocimiento del contexto en el cual se encontraban, porque después de sufrir la exclusión de la educación religiosa en las escuelas, se les propuso una ley que la restituía, pero ellos querían más bien una ley que estableciera lo siguiente:

33 "Acuerdo de la Unión del Clero de Costa Rica," El Mensajero del Clero, 31 de mayo de 1892. $1^{\circ}$ Que decrete la enseñanza católica en las escuelas, colegios y universidades del Estado.

$2^{\circ}$ Que garantice a la Iglesia el cumplimiento del deber que tiene de dirigir, en todo concepto, la enseñanza religiosa en los establecimientos de educación pública y privada.

$3^{\circ}$ Que asegure al clero el libre ejercicio del derecho que tiene de inspección en las demás asignaturas a fin de que nada se oponga a la doctrina católica ${ }^{34}$.

Esta solicitud firmada por los clérigos que conformaban la "Unión del Clero" era imposible. La realidad del país era otra, el mismo ministro de Culto Manuel Vicente Jiménez Oreamuno, le había explicado a Thiel en una carta que la potestad de supervisar el sistema educativo era únicamente estatal (Sánchez 2013).

Como era predecible ni lo propuesto por Rodríguez Zeledón, ni lo solicitado por el clero fue aceptado en el Congreso Nacional. Por ende, mediante la fuerza y como signo de querer cerrar este asunto que tantos problemas le había causado, el presidente de la república, por su propia voluntad luego de cerrar el Congreso y a pocos días de suspender el orden constitucional, firmó un decreto el 4 de agosto de 1892 en el cual se establecía:

34 ANCR, Asamblea Legislativa, sign: 003956, 1892. 
Artículo $1^{\circ}$. -Establécese en las escuelas primarias de Estado la enseñanza del Catecismo Cristiano y de la Historia Sagrada, impartida por los respectivos maestros, con la extensión que en el Reglamento, texto y programas le dé la Secretaría de Instrucción Pública, previo informe de la autoridad eclesiástica.

Artículo $2^{\circ}$. -Esta enseñanza se dará á los alumnos de ambos sexos cuyos padres, tutores ó encargados no manifiesten por escrito, y en la forma reglamentaria, decisión en contrario.

§ Queda sin efecto el acuerdo número 81 de 13 de junio de 1890, que en distinta forma estableció la misma enseñanza.

En unión a dicho decreto Ejecutivo el presidente dispuso de nuevos programas para la instrucción de la Doctrina Cristiana y la Historia Sagrada según cada grado, desde primero hasta sexto. Se establecía que la educación religiosa se daría en las escuelas del Estado, dividida de manera en que los tres primeros años se hubiesen dado explicaciones cortas y familiares de fe y en los últimos tres años los estudiantes deberían tener aprendido "el Catecismo, la Doctrina Cristiana y lectura explicada del texto de Historia Sagra$\mathrm{da}^{35}$ ". Además, el total de horas por semana se fijó en tres, dividido en media hora los lunes, miércoles y viernes para el "Catecismo". Mientras que los mar-

35 República de Costa Rica, Decreto LXXII, del 4 de agosto de 1892, 101-3. tes, jueves y sábados, las lecciones impartidas serían también de media hora cada día, pero para la materia de "Historia Sagrada". En el artículo 4 se estableció los libros por utilizar; es decir, durante los tres primeros años se usaría "Catecismo Abreviado de la Doctrina Cristiana” escrito por la Diócesis de San José y el "Compendio de Historia Sagrada" por Federico J. Knecht; para los años 4, 5 y 6 los libros serían: "Catecismo de la Doctrina Cristiana", escrito por Mons. Thiel y "Historia de la Sagrada del Antiguo y Nuevo Testamento del Dr. Schuster".

De esta manera, la educación religiosa fue restaurada en las escuelas públicas. Esto produjo tanta satisfacción al obispo como a "La Unión Católica" que dicha agrupación organizó, con gran emotividad, un Te Deum el 21 de agosto, ya que se llevó adelante una de las más importantes peticiones de Roma, hacer restituir la Educación Religiosa en las escuelas del Estado. Esta emotividad respondía a que se cumplía lo que León XIII solicitaba al mundo católico, evitar la secularización. Esto mediante el permiso extendido desde Roma a los padres de enviar a sus hijos a escuelas que no ocasionaran tanto daño en su formación religiosa (Picciaredda e Alberti 2006, 27-38). Hecho que sucedía en Costa Rica, donde el sistema educativo, aunque no estaba bajo la supervisión total del clero, si permitía la instrucción de la Doctrina 
Cristiana e Historia Sagrada desde un punto de vista católico.

Para el presidente el problema de la Educación Religiosa no acaba ahí, ya que, si la restituía debía preparar a los futuros profesores. Por este motivo y mediante el Acuerdo CCCIII, del 2 de setiembre de 1892, establecía en la Sección Normal del Liceo y Colegio de Señoritas la enseñanza religiosa. Para ello publicó lo siguiente:

$1^{\circ}$ - Establecer en la Sección Normal del Liceo de Costa Rica y Colegio Superior de Señoritas, la enseñanza de las asignaturas mencionadas en dicho decreto.

2o- Se dedicarán á esta asignatura tres horas por semana en cada uno de los tres primeros cursos de la misma sección.

3o- Corresponde al curso preparatorio la explicación histórica del Antiguo Testamento; al 1er. año, la del Nuevo Testamento, y a1 2o- la de la Doctrina Cristiana.

$4^{2}$ - Las lecciones se ajustarán en un todo á los programas que oportunamente dictará esta Secretaría.

5- Mientras no puedan encargarse estas enseñanzas á maestres normales, se nombrará un profesor al efecto. (Compilación Legislativa de instrucción primaria 1893, 120)

Esta disposición fue llevada a la práctica incluso por medio de otros gobiernos liberales. Por ejemplo, el mismo Ascensión Esquivel Ibarra, quien gobernó de 1902-1906 y de Cleto González Víquez, presidente entre 1906-1910, además de Ricardo Jiménez, mandatario entre los años de 1910-1914, establecieron los siguientes acuerdos: Acuerdo CXXI, del 13 de junio de 1905, creaba la plaza de profesor de Religión y Moral en el Colegio Superior de Señoritas, bajo la dirección del presbítero Lic. don Ricardo D. Zúñiga, con un salario de $\$ 75$ al mes, que se pagará de eventuales de Cartera de Culto del Presupuesto Nacional (República de Costa Rica, Acuerdo CXXI, del 13 de Junio de 1905, 285-286). El Acuerdo CDIII, del 28 de marzo de 1907, organizaba el personal docente del Liceo de Costa Rica y el Colegio Superior de Señoritas, donde se asignaba de nueva cuenta a Ricardo Zúñiga profesor de Religión en el Colegio Superior de Señoritas ${ }^{36}$. Por su parte, el Acuerdo DCCCXCVI, del 5 de marzo de 1908, establecía de nuevo a Zúñiga como profesor de Religión de dicha institución ${ }^{37}$. Por último, está el caso del Acuerdo XIV, del 28 de febrero de 1913, que reorganizaba el plan de estudios, en la Escuela Normal de Señoritas y establecía de nueva cuenta la Educación Religiosa parte de su maya curricular ${ }^{38}$.

36 República de Costa Rica, Acuerdo CDIII, del 28 de marzo de 1907, 257-9.

37 República de Costa Rica, Acuerdo DCCCXCVI, del 5 de marzo de 1908, 147-8.

38 República de Costa Rica, Acuerdo XIV, del 28 de febrero de 1913, 134-5. 
Por último, Thiel aprovechó las facilidades que daba Rodríguez y le pidió permiso para el reingreso de la Orden de los Paulinos, para que se hicieran cargo del Seminario Menor y Mayor de la diócesis. La respuesta del presidente fue afirmativa, se le informó a Thiel el 15 de noviembre de 1892 , mediante Manuel Jiménez

Secretario de Estado en el Despacho de Culto... que no hay ningún inconveniente en el ingreso al país de los profesores enunciados que vienen a encargarse de la dirección del Seminario y que por el contrario aquí encontrarían la protección del Gobierno en el desempeño de la noble misión que se les ha confiado ${ }^{39}$.

$\mathrm{Al}$ año siguiente, 1893, el mismo Jiménez permitía la llegada de una congregación femenina que se haría cargo de una escuela mixta en el Puerto de Limón ${ }^{40}$.

Estos hechos no fueron sinónimo de que el obispo haya quedado conforme con todo lo dispuesto. En el mes de noviembre de 1893, Thiel le solicitó de manera directa al presidente la eliminación por completo de la prohibición al clero de intervenir en el resto de materias de la malla curricular de la educación pública. La respuesta del

39 AHABAT, Fondos Antiguos, sin indizar. Caja 19, folder diciembre 1892. San José 15 de noviembre de 1892. Ff. 91-91v.

40 AHABAT, Fondos Antiguos, sin indizar. Caja 19, folder 1893. San José 7 de enero de 1893. Ff. 11-11v. presidente fue negativa y el 12 de ese mismo mes Thiel indicó que esa respuesta era sinónimo de la visión liberal de Rodríguez, el prelado indicó que:

(...) hace por fin luz en la cuestión enseñanza y demuestra que el Señor Presidente sigue los principios de la escuela Liberal moderna que atribuye al Estado únicamente toda intervención en ella, excluyendo lo que la Yglesia reclama para los niños católicos.

Por último, Thiel agregó que el proceder del gobierno de Rodríguez, en la cuestión educacional, era como el de un tirano, ya que no daba una prueba de libertad, pues mostraba una "inconsistencia con los principios del Liberalismo cuyo credo profesa ${ }^{41}$ ". Este pensamiento Thiel lo expresó en una carta (en latín) al Cardenal Rampolla, Secretario de Estado de la Santa Sede, en 1892, donde indicaba que Rodríguez había dado libertades a la Iglesia en educación, pero no todas las que él esperaba. En síntesis, indicó que:

Presidente de la República apellidado Rodríguez, es hombre bastante religioso ya que todos los domingos asistía a misa en la Iglesia Catedral. En el año de 1890 y otra vez en el año de 1892 este nuevo Presidente sancionó las leyes por las cuales se ordenaba que se enseñara de nuevo religión en las

41 AHABAT, Fondos Antiguos, sin indizar. Caja 19, folder, diciembre 1892. San José, 9 de diciembre de 1892. Ff. 90-90v. 
escuelas públicas. Estas leyes serán perfectas cuando se permita a la Iglesia inspeccionar las escuelas. Espero obtener esto poco a poco en el interim... ${ }^{42}$

\section{A modo de conclusión: ¿Qué} quería Thiel realmente del Estado y de la Educación Religiosa? Evitar la secularización...

Lo visto hasta el momento deja varias conclusiones, pero también una duda principal: ¿por qué el Obispo, luego de 1892, con el decreto ejecutivo ya en función, le indicó a Roma que aún no estaba del todo satisfecho con lo que había conseguido y que el presidente actuaba como un dictador, si más bien este le dio, técnicamente, lo que el clero pedía? La respuesta se encuentra en la vigésima segunda Carta Pastoral de Thiel, publicada el 4 de octubre de 1891. Documento que tuvo como objetivo dejar claro cuál era la verdadera y genuina escuela católica, y, por ende, el objetivo final de Thiel.

Bernardo Augusto Thiel tenía claro qué era la secularización, por ende, la evitó a como diera lugar. Él sabía que sacar a Dios de las escuelas era el primer paso que se daría para luego consolidar la separación entre la Iglesia y el Estado. Si esto sucedía se consumaría de manera definitiva la aconfesionalidad del Estado, así como también la

42 ASCAES, 1888-1893, Pos. 68-75, fasc. 17. F. $48 \mathrm{v}$. posibilidad del tránsito de buena parte de la población del país a la secularización, la cual tenía como fin último sacar del ámbito público a Dios, lo religioso y la moral cristiana, lo cual era inaudito para este obispo romanizado. Por esto, Thiel luchó contra la educación "laica" o neutra. Para Thiel, y en unidad de pensamiento con el Obispo de Roma (Thiel cita a León XIII), este tipo de educación era un "método falso y muy pernicioso sobre todo en los primeros años [de edad], porque en realidad abre el camino al ateísmo mientras que lo cierra a la Religión" (Thiel, en Soto 2014, 455). Para el mismo Thiel "un maestro no católico, indiferente, incrédulo, o librepensador, no comprende al niño católico" (Thiel, en Soto 2014,464 ), ya que aun suponiendo que no quisiese infiltrarle sus ideas, no era funcional para la sociedad católica, porque no educaba bajo los principios católicos. Thiel proponía que todo maestro debía ser un modelo para sus estudiantes y un acatólico no sería el mejor y más deseado ejemplo por seguir para la niñez católica costarricense. Lo anterior unido al hecho de que Pio IX, en el Syllabus, ya había condenado la escuela "laica" en las propuestas 45, 47 y 48 (Rossi 1957, 42-3) por sustraer completamente la escuela de la dirección de la Iglesia y estar sometida por completo a la autoridad estatal, de igual forma por enseñar única y exclusivamente lo natural, dejando por fuera la doctrina cristiana y, por último, por 
ser enseñanza al gusto, al gusto del partido dominante, de las opiniones de la época sin contemplar la fe (Thiel, en Soto 2014).

¿Entonces qué quería Thiel de la Educación? El obispo perseguía incesantemente que no se sacara a Dios del espacio público. Que Dios siguiera presente en la educación y que la Iglesia católica -su verdadera religión-, siguiera teniendo injerencia en el proceso educativo.

Thiel tenía claro que, ni él, ni la propia Iglesia podían convertir a los recintos escolares en formadores de beatos, pero sí de "hombres aptos y competentes en todo ramo del saber humano, y a la vez firmes en sus convicciones religiosas" (Thiel, en Soto 2014, 455). Para él, esto solo se lograría a través de la educación religiosa, la cual perseguía dos fines en particular: 1) preparara todas las personas para vivir en esta vida, y 2) conseguir la salvación para vivir la eternidad que espera en el Reino de los Cielos. En su vigésima segunda Carta Pastoral indicó que el hombre (ser humano) estaba "en la tierra para conocer, amar y servir a Dios en esta vida y alcanzar así la felicidad del cielo" (Thiel, en Soto 2014, 448), por ende, debía ser educado desde la niñez en la rigurosa lógica de alcanzar la vida eterna. El segundo fin era para que, en el devenir histórico de las gentes en la tierra, estas fuesen personas de bien para toda la sociedad, ya que esto, le permitiría alcanzar la vida eterna. De otra manera, Thiel no comprendía cómo se lograría este fin máximo si se separaba o expulsaba a Dios y su verdadera religión de las aulas de las escuelas públicas, pues para él la norma de lex orandi, lex credendi, debía de llevarse no solo en lo privado, sino también en lo público, porque junto a la educación vigilada por la Iglesia y secundada por el Estado, evitarían trastornos en el orden social y moral (Thiel, en Soto 2014). Por tanto, sería gracias a la pedagogía católica que se llegaría a que todos los alumnos pudieran ser ordenados y encarrilados por "el camino de la virtud a efecto de que el hombre, cuando haya llegado a la edad madura sepa conducir su misión terrenal con propia convicción y conciencia" (Thiel, en Soto 2014, 452). Todo lo anterior Thiel lo presentaba dentro del marco de la premisa de la restauración del orden medieval y corporativo propuesto por León XIII (Picciaredda e Albeti 2006).

Para llevar este orden de cosas, el Ordinario de San José proponía que los órganos encargados de educar a la juventud eran los padres de familia, la escuela, la Iglesia y el Estado. Sobre los padres argumentó casi lo mismo que había expresado en su carta pastoral número 14,-ya explicada en este trabajo-, pero, sobre las escuelas indicó que debían de ser por obligación católicas y dirigidas por católicos. Esto con el 
objetivo de que no se diesen contradicciones en lo que se veía en las casas católicas y lo que se enseñaba en las escuelas públicas. Este argumento es obvio, Thiel lo que perseguía era cancelar la salida de Dios de las aulas, para eliminar la posible secularización. El obispo reforzó al hablar de la unión que debía existir entre Estado e Iglesia, en la tarea de educar a los jóvenes. El Ordinario indicaba que, desde su origen, la Iglesia Católica era, por excelencia, el gran instrumento educacional del género humano, ya que, el mismo Dios Hijo la fundó bajo este criterio al decirle a sus apóstoles "Idos al mundo entero a enseñad a todas las naciones" Dicha labor la desempeñaba ahora en unión con el Estado, por la obligación e interés de este en imponer prescripciones necesarias para sus gobernados, según fuese su realidad.

Para el obispo y al seguir las ideas expresadas en las encíclicas papales de León XIII "Immortale Dei" (Inmortale Dei, León XIII, 1885), y "Sapientiae christianae" (Sapientiae Christianae de León XIII, 1890), cada Estado sabía lo que necesitaba, como por ejemplo las "escuelas militares, de ingeniería y arquitectura, industriales y otras", pero siempre con la supervisión del credo católico en las escuelas elementales, normales, superiores y universidades, para preservar el carácter católico de

43 Mt 28, 19, según la traducción de la Vulgata de San Jerónimo. los centros de enseñanza (Thiel, en Soto 2014,465$)$. Esto último es lo que anhelaba Thiel, que la educación existiera, que se desarrollara, que creciera, pero que no se sacara a Dios de esta.

Mediante el accionar de Thiel, unido a la colaboración brindada de manera directa e indirecta por el clero, feligreses y políticos liberales (estos últimos quisieran o no, se enteraran o no), logró poner un cierto freno al proceso de secularización, aunque no fue total, pero freno al fin. Al punto que hoy la sociedad costarricense no es una sociedad secularizada, la visión religiosa sigue, de una u otra manera, presente en lo público y en lo privado. La labor de Thiel, del clero, de los feligreses y de los políticos en estos 9 años de historia, generó varios resultados. En primer lugar, se mostró el músculo político y poder movilizador que tenía la jerarquía católica. Esta movilización se mostró en la matrícula a los centros educativos. Para el año de 1891, Manuel Obregón Lizano, inspector de las escuelas del Estado indicó que, en Tibás, la matricula había descendido a causa del accionar del clero (Sánchez 2013). En 1892 se restableció la enseñanza religiosa en las escuelas públicas, hecho que, al unirse con la recomendación de Thiel a los padres de familia católicos de volver a matricular a los niños en dichos centros, permitió "que la matrícula en las escuelas públicas empezara a recuperarse" (Molina 
2016b, 153), después del golpe que había sufrido la matrícula por la lucha con el catolicismo.

La otra gran conclusión a la que se llegó fue: el comprender cómo se dio el proceso para los pactos y el consenso entre la jerarquía católica y el Estado. Dentro de los 9 años analizados (1883-1892) se demostró los "estiras" y "encojes", las pugnas y los acercamientos, y en particular los entretelones, de ambas instituciones para conseguir un fin en particular que las involucraba a ambas. De parte de la clerecía se persiguió siempre la reincorporación de las materias de Doctrina Cristiana e Historia Sagrada, así como la injerencia eclesial en toda la educación. Este objetivo se consiguió a medias, pero se consiguió, como ya se dijo, se frenó, en cierta medida la secularización. Por parte de los actores políticos los objetivos eran varios. Por ejemplo, erradicar a la jerarquía católica del escenario político y el otro era "sacar" provecho del poder del catolicismo en el país para llegar a un fin político, todo esto se consiguió, pero a medias. Por ende, la conclusión es que dentro de la relación Estado-Iglesia la principal característica que reinaba era el consenso; a como se podía ganar en un punto se podía perder en otro como lo demostró este artículo, lógica que aún funciona en sus relaciones.

\section{Bibliografía}

Arce, Celin. 1997. El derecho Educativo. EUNED, San José Costa Rica.

Delgado, Buenaventura. 1998. Historia de la Infancia. Barcelona: Ariel Editores.

Blanco, Ricardo. 1984. 1884 El estado, la iglesia y las reformas liberales. Editorial Costa Rica, Costa Rica.

Conti, Fulvio. 2003. Storia della Massoneria italiana, dal Risorgimento al Fascismo. Il Mulino, Bologna, Italia.

De la Cruz, Vladimir. 2009. "La educación y la cultura costarricense en el siglo XIX: de las Cortes de Cádiz a las reformas educativas", En: Salazar, Jorge Mario (ed), Historia de la educación costarricense San José: Editorial de la Universidad Estatal a Distancia, 1-72.

Fischel, Astrid. 1990. Consenso y represión: una interpretación socio-política de la educación costarricense. San José: Editorial Costa Rica.

Gonzalbo Aizpuru, Pilar. "Buenos cristianos y jóvenes letrados en Santa Cruz de Tlatelolco". En: Pablo Rodríguez y Emma Mannarelli. 2007. Historia de la Infancia en América Latina. Bogotá: Universidad Externado de Colombia, 107-120.

González Flores, Luis Felipe. 1959. "Historia de la educación en Costa Rica”, Educación, n¹3, marzo-abril. 
Martínez Esquivel, Ricardo. 2009. "Documentos y discursos antimasónicos católicos en Costa Rica (18651899)" REHMLAC Vol. 1, № 1, Mayo 2009-Noviembre, 135-154.

Martínez Esquivel, Ricardo. 2017. Masones y masonería en la Costa Rica de los albores de la modernidad (1865-1899). EUCR. San José, Costa Rica.

Mallimaci, Fortunato. 2004. Catolicismo y liberalismo: las etapas del enfrentamiento por la definición de la modernidad religiosa en América Latina. In: Bastian, Jean Pierre (coord.) La modernidad religiosa: Europa latina y América Latina en perspectiva comparada, Fondo de Cultura Económica, México.

Molina Jiménez, Iván. 1989. "El 89 de Costa Rica: otra interpretación del levantamiento del 7 de noviembre", Revista de Historia de Costa Rica, No. 20, julio-diciembre.

Molina Jiménez, Iván. 2016. La educación en Costa Rica de la época colonial al presente. EDUPUC, San José, Costa Rica, 143, 153.

Murillo Guzmán, Luis. 2017. La participación de los sacerdotes y la jerarquía católica de Costa Rica en las contiendas político-electorales presidenciales 18891914. Trabajo en progreso.
Picciaredda, Stefano e Alberti, Vittorio. 2006. Il mondo di Leone XIII. L'incontro della Chiesa con il XX secolo. Edizioni Liberal.

Quirós, José Alberto (ed.). 2002. Datos cronológicos para la historia eclesiástica de Costa Rica: por Bernardo Augusto Thiel. San José: Ediciones CECOR.

Rossi, Ernesto (a cura di). 1957. Il Sillabo, Parenti, Firenze.

Sanabria Martínez, Víctor. 1982. Bernardo Augusto Thiel, II Obispo de Costa Rica. (Apuntamientos Históricos), San José, Costa Rica, Editorial Costa Rica.

Sánchez Solano, Esteban. 2013. La participación político-partidista de la Iglesia: El Partido Unión Católica y sus estrategias de movilización política en el marco del conflicto entre la Iglesia católica y el Estado liberal en Costa Rica (1889-1898), Tesis de Maestría Universidad de Costa Rica.

Sandí Morales, José Aurelio.2012. Estado e Iglesia católica en Costa Rica 1850-1920; en los procesos de control del espacio geográfico y la creación de un modelo de costarricense, Publicaciones Universidad Nacional, Heredia, Costa Rica.

Sandí Morales, José Aurelio.2010. Las leyes anticlericales de 1884 en Costa Rica; una relectura desde otra perspectiva. SIWO, № 3, 59-100. 
Sandí Morales, José Aurelio. 2016. "Costa Rica en la geopolítica de la Santa Sede, La representación papal en Centroamérica entre 1908-1936". Espigas Año XV, № 32 Diciembre, 81-102.

Sandí Morales, José Aurelio. 2018. La Santa Sede in Costa Rica 1870-1936. Il rapporto politico-religioso e diplomatico tra il governo del Costa Rica, la gerarchia cattolica del Paese e la Santa Sede nel periodo liberale costaricano. Tesi di dottorato. Scuola Normale Superiore di Pisa. 2017.

Sandí Morales, José Aurelio. 2009. La Diócesis de San José y el Estado costarricense: la creación de parroquias y el control del espacio geográfico nacional, el surgimiento, difusión y consolidación de un ideario de costarricense para arraigar el proyecto Estado-Nación (1850-1920). Tesis para optar por el grado de Magíster Scientiae, Universidad Nacional.

Solano Muñoz, Edgar. 1993. Iglesia, sociedad y relaciones de poder en Costa Rica 1881-1894, Tesis de Licenciatura en Historia, Universidad Nacional, Heredia, Costa Rica.

Solano Muñoz, Edgar. 2010. "La participación del clero costarricense en las campañas políticas de 1889 y 1894", Diálogos Revista Electrónica de Historia, vol 11, num 2, set-feb., 5-21.
Thiel Hoffman, Bernardo. 2014. Décima cuarta pastoral, 20 de enero de 1888 En: Soto Valverde, Gustavo. El pensamiento social y político de Monseñor Bernardo Augusto Thiel. Imprenta y Litografía Lil, San José, Costa Rica.

Thiel Hoffmann, Bernardo. "Monografía de la población de la República de Costa Rica en el siglo XIX". Revista Población y Salud en Mesoamérica.Vol. 9. (2011) n. 1, julio-diciembre, San José: UCR), 64 y González, 40-1. Citado por: Iván Molina, "Poderes y educación en Costa Rica a finales del período colonial" En: David Díaz y Ronny Viales (eds) 2012. Independencias, estados y políticas en la Centroamérica del siglo XIX. Las huellas históricas del Bicentenario. San José, CIHAC.

\section{Fuentes de archivo}

\section{Congregazione degli Affari}

Ecclesiastici Straordinario (ASCAES)

Archivio Storico, Congregazione degli Affari Ecclesiastici Straordinari, Costa Rica. 1888-1893, Pos. 6875, fasc. 17. F. 48v. Impreso.

ASCAES, Costa Rica, 1884, Facs. 4 Pos. 51-56, ff. 68-69.

ASCAES, Costa Rica, 1884, Facs. 4 Pos. 51-56, ff. 72-77.

ASCAES, Costa Rica, 1884, Facs. 5 Pos. 57. ff. 7-8. 
ASCAES, Costa Rica, 1885-1886, Facs. 11, Pos. 64-66. ff. 4, 10. Impreso.

ASCAES, Costa Rica, 1884-1885, Facs. 8, Pos. 58. ff. 5-5v. Impreso.

ASCAES, Costa Rica, 1885-1886, Facs. 1, Pos. 64-66. ff. 57.

\section{Archivo Histórico Arquidiocesano \\ Bernardo Augusto Thiel (AHABAT)}

AHABAT. Fondos Antiguos, Caja 389. San José 12 de octubre de 1889. Folio 350.

AHABAT. Fondos Antiguos, Caja 389. San José 15 de octubre de 1889. Folio 362-365v.

AHABAT. Fondos Antiguos, Caja 389. San José 5 de octubre de 1889. Folio 340. Impreso.

AHABAT. Fondos Antiguos, sin indizar. Caja 19. San José 15 de julio de 1890. Folio 157.

AHABAT. Fondos Antiguos, sin indizar. Caja 19, folder diciembre 1892. San José 15 de noviembre de 1892. Ff. 91-91v.

AHABAT. Fondos Antiguos, sin indizar. Caja 19, folder 1893. San José 7 de enero de 1893. Ff. $11-11 \mathrm{v}$.

AHABAT. Fondos Antiguos, sin indizar. Caja 19, folder, diciembre 1892. San José, 9 de diciembre de 1892. Ff. 90-90v.

AHABAT. Fondos Antiguos Caja \#48, Folios 31-31v, del 26 de julio de 1853, San José, Costa Rica.

\section{Archivo Nacional de Costa Rica}

(ANCR)

ANCR. Sección: Asamblea Legislativa. Código: CR-AN-AHAL-003956. Fecha: 22-7-1892.

ANCR. Fondo: Colonial. Signatura: 934. Año: 1798, folios 38-39.

\section{Colección de Leyes y Decretos:}

República de Costa Rica. Leyes y Decretos de Costa Rica. 6 de abril de 1825 .

República de Costa Rica. Leyes y Decretos de Costa Rica. 19 de mayo de 1847.

República de Costa Rica. Leyes y Decretos de Costa Rica. 26 de noviembre de 1869.

República de Costa Rica. Leyes y Decretos de Costa Rica. 26 de noviembre de 1869.

República de Costa Rica. Leyes y Decretos de Costa Rica. 22 de julio de 1884 .

República de Costa Rica.Colección de la Leyes y Disposiciones Legislativas y Administrativas emitidas en el año de 1884. Edición Oficial. Imprenta Nacional, 1885.

República de Costa Rica. Acuerdo CXXI, del 13 de Junio de 1905. Colección de Leyes y Decretos. Edición Oficial. Primer Semestre de 1905. Tipografía Nacional.San José, Costa Rica. 1905. 285-286. 
República de Costa Rica. Acuerdo CDIII, del 28 de marzo de 1907. Colección de Leyes y Decretos. Edición Oficial. Primer Semestre de 1907. Tipografía Nacional.San José, Costa Rica. 1907. 257-259.

República de Costa Rica. Acuerdo DCCCXCVI, del 5 de marzo de 1908. Colección de Leyes y Decretos. Edición Oficial. Primer Semestre de 1908. Tipografía Nacional.San José, Costa Rica. 1908. 147-148.

República de Costa Rica. Acuerdo XIV, del 28 de febrero de 1913. Colección de Leyes y Decretos. Edición Oficial. Primer Semestre de 1913. Tipografía Nacional.San José, Costa Rica. 1913. 134-135.

\section{Referencias electrónicas:}

Inmortale Dei, del sumo pontífice León XIII,1885. Disponible en: $<$ http://w2.vatican.va/content/ leo-xiii/es/encyclicals/documents/hf_l-xiii_enc_01111885_ immortale-dei.html>

Sapientiae Christianae Encyclical of Pope Leo XIII, 1890. Disponible en: <http://w2.vatican. $\mathrm{va/content/leo-xiii/en/ency-}$ clicals/documents/hf_1-xiii_enc_10011890_sapientiae-christianae.html>

\section{Periódicos}

1883. La escuela sin enseñanza religiosa, ó la ciencia sin Religión. El Eco Católico, San José, 17 de febrero, año. I, № 7 .

1883. Los Principios Masónicos aplicados en Costa-Rica. El Eco Católico, San José, 31 de marzo, año. I, № 12 .

1883. El verdadero Progreso es debido en su mayor parte al Catolicismo. El Eco Católico, San José, 17 de febrero, año. I, № 7 .

1884. La enseñanza monacal. El Eco Católico, 19 de enero.

1890. Breves disertaciones sobre la enseñanza laica. El Eco Católico, San José, 11 de enero de 1890, año. III, № 101.

1890. Breves disertaciones sobre la enseñanza laica. El Eco Católico, San José, 18 de enero, año. III, № 102.

1890. El catolicismo y la Enseñanza. El Eco Católico, San José, 25 de enero, año. III, № 103.

1890. La enseñanza neutra no es neutra. El Eco Católico, San José, 1 de febrero, año. III, № 104 .

1890. Señor Secretario de Culto Lic. Don Ricardo Jiménez, San José. Sipurio de la Talamanca á 9 de Enero de 1890. El Eco Católico, San José, 8 de febrero, año III, no 105 . 
1891. Actitud de la jerarquía católica en Estado Unidos con las escuelas públicas. El Mensajero del Clero, San José 31 de enero, №. 29, Año II.

1891. La Unión del Clero. El Mensajero del Clero, San José, 31 de mayo, №. 45, Año IV.

1892. Acuerdo de la Unión del Clero de Costa Rica. El Mensajero del Clero, San José 31 de mayo, año IV, № 45.

\section{Leyes y documentos primarios varios}

Ley General de Educación Común. San José, Costa Rica, 1886, 2.

Compilación Legislativa de instrucción primaria. San José. Tipografía Nacional. 1893, 120.

"El Ayuntamiento de Cartago sobre el acertado Gobierno de don Tomás de Acosta" Revista de los Archivos Nacionales, N7-12, julio diciembre, (1950), 45.

Actas del Ayuntamiento de Cartago 1800-1810: Protesta del Pbro. José María Esquivel por el nuevo salario que le ha señalado el Cabildo" Revista de los Archivos Nacionales, $\mathrm{N}^{\circ} 1-6$, enero-junio (1959), 13. 